\title{
La pedagogía que yo quiero
}

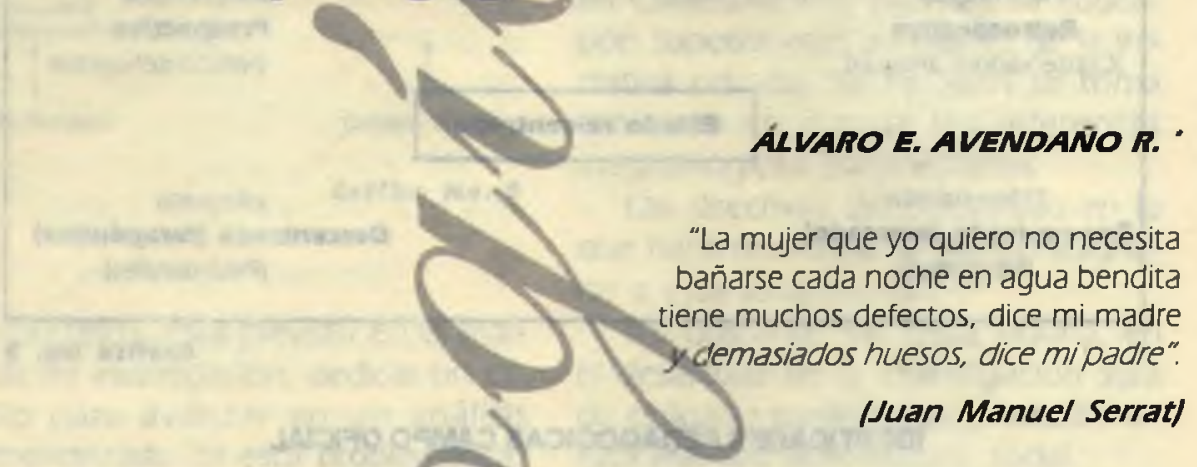

Repasando los recientes acontecimientos universitarios, recuerdo, no sin nostalgia, estos versos que nos acompañaron en los 70. Y es que el Estado, con la ilusión de los padres de antaño, nos trae las medidas de una novia perfecta, pero sus índices detallados y rostosos informes sólo desnudan los "huesos y defectos" que afean a sus ojps nuestra universidad. Pues no; ella no necesita bañarse en esa agua bendita.

El Estado, en su paternal vanidad, cree que todo debe ser a su imagen y semejanza. Ya es hora de que sus hijo., camo dicen las señoras: "inmaduros y todo", escojamos nuestro destino.

Lo sé porque lo he sufrido, y es a este punto d que quiero referirme. Universidad Surcolombiana. Diciembre de 1999. Gran presentación de iniciativas de postgrado. Ansioso, un grupo de desprevenidos profesores esperaba al evaluador del Consejo Nacional de Acredltación (CNA). Con anterioridad había presentado una propuesta de especialización en el área de la informática para los maestros de la región.

Yo, que era su líder, había dormido pocas horas pensando en el importante pedagogo enviado de la capital: declan que tenía un doctorado en inteligencia artificial, el número uno. Yo hasta festejé con ardor por la estimación que esa especialidad despertaba en mi corazón. Además, cada nueva palabra que aquí escribo me convence aún más qué, sin la inteligencia del procesador de texto que uso, estas líneas ni siquiera seriann legibles.

Sin embargo, mucho más hazañosa que los títulos del evaluador fue la odisea del grupo que presentó el proyecto: no dejamos rincón de Internet sin visitar y sacamos una y otra vez llbros de nuestras bibliotecas, sin olvidar la de algún descuidado amigo. A mi hỉja le compré por encargo en Dinamarca (Jutlandia, no Huila, pôr si acasal. un armotodo- Lego de inteligencia artificial.

* Profesor Titular de la Universidad Surcolambiana. Autor de varios textos universitarios y de artículos publicados en revistas nacionales y regiohales gibre temas educativos y de ecología. 
En fin, en todo se podía palpar el silico ino la silicona, por si hay algún lecior maliciosol.

Acenas el evaluador lanzó su primera pregunta sobre el número de doccores que teníamos en esa área, supe que estábamos en problemas.

No importaba cuántas grandes teas habíamos producido, cuántas sorias pedagógicas habíamos consul[abio. cuántos años llevábamos lideran- $u$ la capacitación en el departamento. a án noble e importante para nuestra a a bin era la propuesta. De todas mameras pendía sobre nuestras cabezas acuella espada de marras, lista a caer, In ringuna otra consideración. Leyeon bien: lespadal. Porque al fin y al abo los títulos recuerdan la edad meda ije espadas y nobles $y$, una vez aduridos. ellos se encargan de cobrar y nacer a otros trabajar para nosotros, 2 igual que los títulos de nobleza.

No es que tengamos inconvenien- en reconocer nuestras limitaciones. 1 IE Encia de las eminencias, que con gamo orgullo exhiben sus proezas cacemicas ejecutadas en los más cula zuditorios del mundo, nosotros no. - isiarros reconocemos que a duras - es podíamos mostrar tres o cuatro Execialistas de fin de semana en Dusatá

Como intuí que nada les gusta más ai los científicos pedagogos que meter - ano en los procesos pedagógicos de us aros. sugerí tímidamente que ellos ocran ser asesores.

- IAsesores nol- con un gesto rápirespondió.

Eueno. no podía ofrecer más sin a corameter las plazas de mis com- veros que me estaban ayudando.
La evaluación debió terminar en ese primer momento, pero no, empezaba la justificación de los viáticos, digo mal, se iniciaban los rigurosos procesos de evaluación que debían prolongarse a lo ancho de tres largos días.

El último día y como último intento de estudiante acorralado, mostramos que habíamos llenado todos los requisitos y cumplido las tareas recomendadas por el CNA. Sin embargo, no logró ocultar nuestra orfandad doctoral en informática.

- iProfesor, profesorl Somos los mejores pedagogos de la región, Lcómo es posible que otros sí tengan aquí estos programas?. ¿Cuántos doctores tenían Uds. cuando empezaron?, IResponda por favor!

No somos los mejores, por supuesto. Este era sólo un ardid para llamar la atención del viejo profesor. Pensamos que, si aún fluía la juvenil pasión científica por sus venas, resucitaría ante sus propios comienzos. Fue inútil. O la edad le había secado las venas, o la rodadita a tierra caliente le había taponado los oídos.

- Quizás, para darnos a entender mejor, lo que necesitamos es un ambiente más relajado. ¿Por qué no discutimos esto en una cena de trabajo? -invitó alguien, haciéndome un cómplice guiño.

Majestuoso, acartonado y lejano, el sabio se negó. Y justo es reconocerlo, en ese instante emitía una luz de esperanza para este país tan falto de moral. Luz que llegó a su máximo briIlo, cuando, al momento de despedirse, sentenció en forma críptica: 


\section{2}

\section{Universidad Surcolombiana}

- ILes deseo suerte en el programal

Pasaron los días, los meses y al fin, cuando incluso nosotros mismos ya lo habíamos olvidado, llegó la carta. Al principio sentí repulsión por ella, pero animado por sus últimas palabras la abrí y, claro, confirmado: era imposible que el poco tiempo que estuvo expuesto a nosotros hubiera producido la milagrosa transfiguración del profesor: Todo estaba en el punto de marras. Lo curioso es que muchas de las razones, por las que se negaba el programa, han recorrido impunemente este país desde hace siglos y nunca se han topado con un retén dispuesto por la descentralización o por las autonomías universitarias.

- Las palabras de despedida -añadió alguien ante el recuerdo del paradigmático profesor- las dijo sólo para encubrir nuestros manifiestos defectos para él.

- Lo negaron, más por desoírnos a nosotros que por otra razón -contradije, delatando al lambón, y agregué-: Sólo al CNA le habrá gustado, porque a mí nunca me cayó bien el profesor. A todos tampoco, aunque no era tan evidente.

Yo examino ese año, y aún no entiendo cómo no hubo ninguna medalla, ninguna condecoración, ningún reconocimiento, ni siquiera de parte de la universidad, para el grupo que, en computadora, en impresos, en las altas horas de la noche, leímos de cabo a rabo todos los documentos del CNA. aunque no hubiéramos podido apoyar el nuestro en los importantes asientos de la especialización. Las únicas que siempre estuvieron pendientes fueron nuestras esposas, no tanto por el interés científico, sino por el que les despertaba las llegadas tarde a casa

Y aquí abandono toda referencia a otros episodios de la negativa -diferentes maneras de cómo las grandes universidades satisfacen sus necesidades negando satisfacerlas a las pobres: pues al fin y al cabo, ¿para qué le sirve a las universidades bogotanas que las de provincia ofrezcan programas que mermen el caudal de estudiantes que, ante la carencia regional de oportunidades, llega a la capital, así sea los fines de semana?-y aporto, desde esta decretada condición marginal, algunas ideas que ayudarán a desarrollar la pedagogía, por si alguien más piensa que valdría la pena recoger.

Las universidades de Bogotá piensan, equivocadamente, que nosotros somos la competencia. En lugar de fortalecernos, para contrarrestar, unidas, el nuevo y continuo desembarco de universidades del viejo continente por la red, nos combaten. Por ello propongo que ayudemos a desembarcar, no únicamente a las del viejo, sino también a las del nuevo continente. Hagamos alianzas de beneficio mutuo, antes de que intenten acabarnos, como lo hiciera algún torpe conquistador de antaño. Una vez firmados los convenios con estas universidades, ya no faltarán los doctores. Después de investigar por más de quince meses, hemos elaborado una exclusiva lista de universidades del mundo donde sobran llas de Bogotá, por obvias razones, no aparecen en ella). De esta forma la globalizacion ya empieza a tocarnos.

A propósito, estuve hablando con una linda egresada que también se pasea en universidades por el mundo. Cuando ella prometió ayudarnos, la alegría que me desbordaba hizo pensar entonces a un compañero transeúnte 
Paideia Surcolombiana

que ella estaba aceptando por lo menos un fin de semana en los balnearios de Rivera.

- La universidad debe apoyar el programa -aconsejó ella

- No nos ponga imposibles repliqué.

Y es que nadie en la universidad esus:o pendiente del programa. Era una orfandad apenas superada por la de los doctores. Mas que una propuesta, parecía una cruz que debíamos llevar our el calvario de las oficinas, por haberla creado. Soy socio de algunos clubes, lo confieso, pero tampoco puedo negar que nos permitieron utilizar nuestras oficras: no nos prohibieron, durante el aempo de trabajo, elaborar la propues-a y de igual manera, no nos tocó pagar las llamadas ni las conectadas a intemet, iesperel. creo que eso sí.

Nuestros esfuerzos fueron en vano. Dero no es nuestra responsabilidad. Ion tanta universidad ofreciendo por ah il estos postgrados, yo creo que falza un compromiso de la misma instituabin. Yo entendería esta falta de interés si se tratara de un noticiero, pues al in y al cabo nuestro grupo no era de - codelos, no cantamos ni en las dumas, nunca asaltamos bancos y nunze pronunciamos discursos políticos.

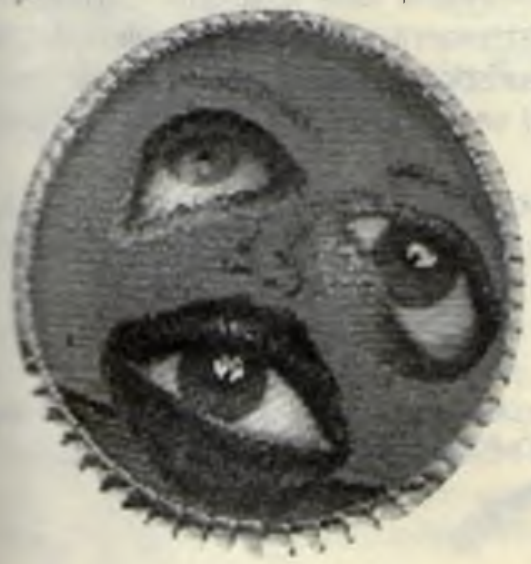

No he recorrido suficiente mundo como para saber si en las escuelas de otros países los niños aprenden himnos como "la Virgen sus cabellos, arranca en agonía, y de su amor viuda, los cuelga del ciprés...", pero no me cabe duda de que este himno es colombiano, y lo sé porque la Virgen no podía colgar sus cabellos del guamo, que es muy colombiano, sino que tenía que hacerlo de un árbol mediterráneo: el ciprés. También lo sé, porque nunca lo entendí.

Cuando lleguen los aliados europeos, lo primero que vamos a hacer es cambiar todos los incómodos asientos universitarios por hamacas, así sean virtuales. Los adustos contenidos de física no podrán seguir siéndolo. Óigase bien, no podrán ser presentados como: "Cuarta Ley de Newton: la ley de la gravedad", sino muy al estilo colombiano: "cómo mamarle gallo a la ley de la gravedad".

Se premiará la habilidad de la escuela de invadir fiestas y parrandas, de erradicar la pedagogía extraña que vanamente ha luchado contra nuestra Latinidad, de hacerla ver como algo malo y pernicioso, en lugar de lo que es: un soporte firme de nuestro puesto en la fiesta mundial de las naciones.

Deploro si he sido demasiado duro con algunos académicos, aunque oigo decir que en esta materia nunca se es demasiado duro. Empiezan delirando sobre la infalibilidad de la razón, continúan confundiéndola con su falible razón y terminan aceptando su mesiánica misión de imponerla. De todas formas, me reconocerán el enorme esfuerzo por tratar estos temas con la elegancia y enorme respeto que ellos imponen.

Debo, por último, confesar que todo lo contado aquí es invención del autor y que si en alguna parte se confunde con hechos reales es pura coincidencia. 